U.S. Department of the Interior

U.S. Geological Survey

\title{
SAMPLE HANDLING AND CURATION PROTOCOL \\ FOR THE \\ CREEDE CALDERA MOAT SCIENTIFIC DRILLING PROJECT
}

by

Wayne R. Campbell ${ }^{1}$

Open-File Report 92-410

This report is preliminary and has not been reviewed for conformity with U.S.

Geological Survey editorial standards (or with North American Stratigraphic Code).

Any use of trade, product, or company names is for descriptive purposes only and does not imply endorsment by the U.S. Government. 
CONTENTS

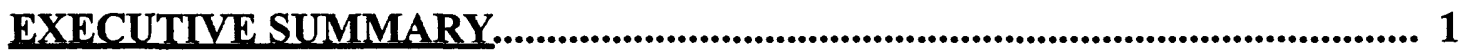

INTRODUCTION ........................................................................................................... 1

DEFINITIONS ................................................................................................ 2

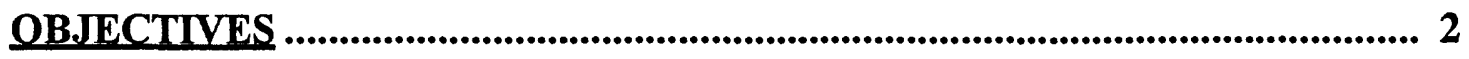

PERSONNEL AND RESPONSIB IUTIES .............................................................. 3

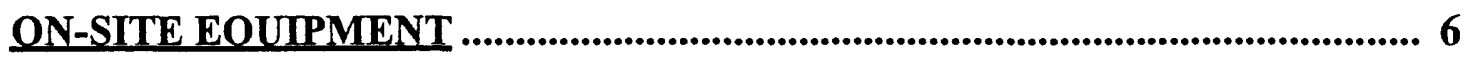

ON-SITE HANDLING AND SAMPLING PROCEDURES ............................... 7

GENERAL STATEMENT ..................................................................... 7

CORE HANDLING PROCEDURES ...................................................... 7

CORE CHARACTERIZATION PROCEDURES ......................................... 12

ON-SITE CORE SAMPLING PROCEDURES............................................. 12

CURATION AND ARCHIVING PROCEDURES ..................................... 12

Working Split ............................................................................................................ 13

Archive Split ................................................................................ 14

True Depth Determination and Marking ..................................................... 14

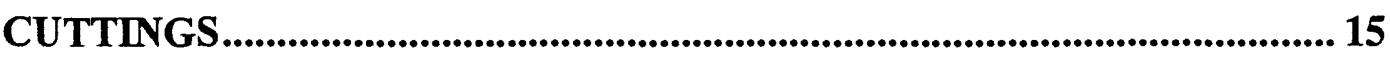

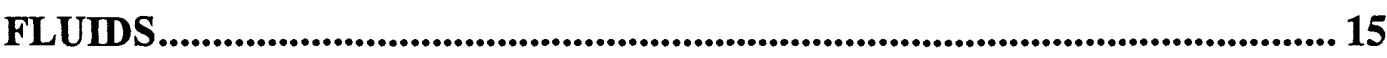

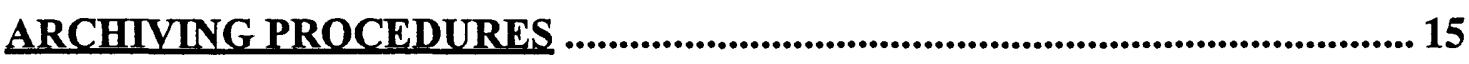

SAMPLE DISTRIBUTION POLICY............................................................ 16

GENERAL STATEMENT ......................................................................... 16

Sampling Limits .................................................................................................... 17

SCIENCE PLAN EXPERIMENTS ................................................................. 17

NON-SCIENCE PLAN EXPERIMENTS ................................................ 17

Sample Requests ................................................................................................... 18

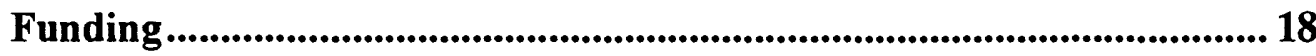

Responsibilities ....................................................................................................... 18

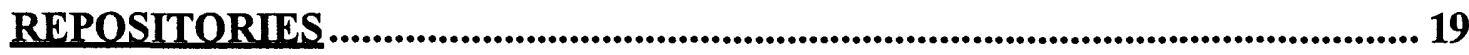

REFERENCE LIBRARY ..................................................................................... 19

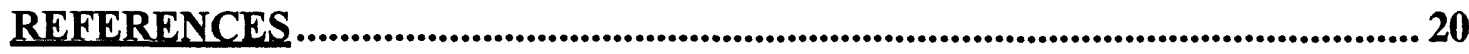

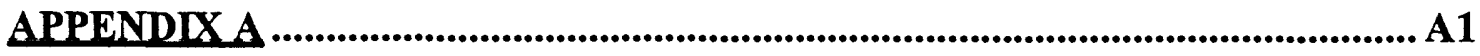

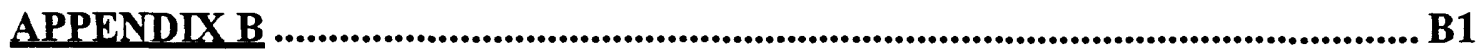


List of Illustrations

Figure 1: $\quad$ Creede Caldera Moat Research Drilling Project's Management Plan .. 4

Figure 2: $\quad$ Flow Diagram for core handling and curation ................................8

Figure 3: Examples of pen marks vs scribed lines to indicate core up/down

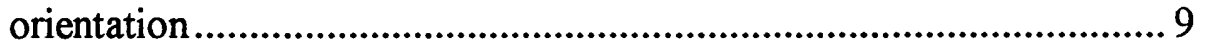

Figure 4: Core sample numbering protocol for the Creede Caldera Moat Drilling Project .................................................................... 11

Figure 5: $\quad$ Examples of pen marks to designate slabbing cut orientation ........... 13

Figure Bla: Example of a completed core log for the Creede Caldera Moat

Research Drilling Project (sheet 1 of 2) ...................................... B2

Figure B 1b: Example of a completed core log for the Creede Caldera Moat Research Drilling Project (sheet 2 of 2) ..................................... B3

Figure B2: Creede Caldera Moat Drilling Project lithologic patterns and number index for the core log sheet "Lithology" column ............................. B4

Figure B3: Explanation of symbols and patterns in core log column entries for the Creede Caldera Moat Research Drilling Project B5

Figure B4: Grain characteristics charts used in Creede Caldera Moat Research Drilling Project core logging sheets

List of Tables

Table 1:

On-site sample processing equipment provided by the USGS 6

Table B1: Abbreviations for the Creede Caldera Moat Research Drilling Project geologic logs. B8

List of Forms

Core Log for Hole CCM-1 (sheet 1 of 2) .................................................... A2

Core Log for Hole CCM-1 (sheet 2 of 2) ................................................... A3

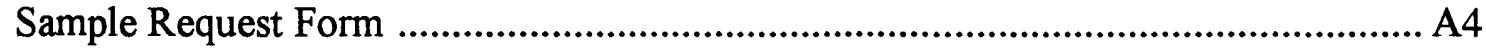

35 mm Photo Log............................................................................... A7

Core-Run Depth Log ............................................................................. A8

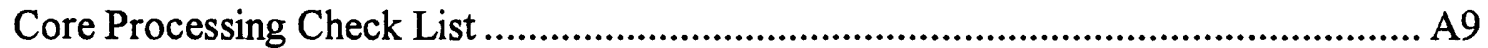

On-site Core Sample Record ................................................................. A10

Drilling Fluid \& Additive Log ..................................................................... A11 


\section{EXECUTIVE SUMMARY}

Studies of samples collected during the U.S. Geological Survey (USGS) Creede Caldera Moat (CCM) drilling project, undertaken by the Interagency Coordinating Group for Continental Drilling (ICG) as part of the U.S. Continental Scientific Drilling Program encompass two time frames: 1) detailed studies during drilling and for two years following hole completion, and 2) later re-examination of samples with new analytical techniques or research objectives. This protocol provides guidelines to insure that the handling and curation of samples is such to permit studies in both time frames. This protocol, together with the project Science Plan, govern sample collection, curation, allocation and archiving for this project.

An on-site USGS Curation Team, under the supervision of the project Sample Manager, will be responsible for initial handling, documentation, and integrity of drilling samples, and for preparation of samples for shipment to the USGS Core Research Center (CRC) in Denver, Colorado. The samples will be split at the CRC to provide a Working Split for experiments by scientists in both time frames, and an Archive Split; both will be curated at the CRC. Access to Samples and Data from the drilling program shall be limited to Principal Investigators and ICG approved Secondary Investigators for a period of two years following completion of drilling.

This protocol describes the responsibilities of the various on-site drilling project personnel for sample collection, establishes on-site handling and curation procedures, lists equipment available for immediate on-site analyses, establishes archiving procedures, and establishes procedures for sample distibution to Principal Investigators following the policy for sample allocation established in the project Science Plan.

\section{INTRODUCTION}

Comprehensive scientific information acquired during the Creede Caldera Moat drilling project will come from core, fluid samples, and down-hole geophysical logs. Careful handling, analysis, and curation of all samples and data are vital to the following critical elements of the U.S. Continental Scientific Drilling Program:

1) Materials and information required to accomplish the science goals of the drilling project.

2) Permanent documentation of the geological, geophysical, geochemical, and hydrological environments encountered in the drill hole.

3) Correlation of sample properties with geophysical, drilling, and mud logs to enhance the interpretation of such logs and allow correlation with results of surface geological, geophysical, geochemical, and hydrological studies. 
4) Timely information to the drilling staff and project scientists to allow possible modifications to the Science Plan to maximize the scientific value of the project.

5) Preservation of samples and relevant data for future scientific studies.

This protocol was modified from DOSECC's "Sample Handling and Curation Protocol" (Appendix 1 [dated May, 1986] in Michalski and Linenberger, 1990) and the "Core Handling Procedures Used for the Cajon Pass, California, Deep Drilling Experiment" (Campbell and Gay, 1989) to meet the specific needs of the USGS Creede Caldera Moat drilling project. That protocol, in turn, was based extensively on curatorial policy guidelines and procedures for the Continental Scientific Drilling Program (Goff, 1985).

\section{DEFINITIONS}

For the purpose of this protocol, samples are defined to include drill core, mud logging samples, and fluid samples and subsamples collected from the drill holes. Data includes lithologic logs and notes, geophysical logs, mud logs, driller's logs, and other measurements or data collected on-site, and results of analyses, notes of observations, etc. collected by Principal Investigators during scientific study of samples following drilling. Core handling is defined as the physical handling of samples from the drill rig to the on-site sample processing and laboratory facilities, to any intermediate archival facilities, and finally to the USGS Core Research Center in Denver, CO. Core characterization includes peicing, marking, boxing and special handling such as waxing, lithologic logging, physical property measurements, core description, etc. made on-site prior to shipment of samples to the CRC. Curation refers to the identification, splitting, boxing, indexing, filing, accession, and deaccession of drilling samples under the control of the USGS both on-site and at the CRC. Principal Investigators. include those scientists whose proposals for study of core or fluid samples or to conduct downhole experiments have been approved by the ICG Science Panel and funded by one of the Agencies, and who are identified in the Science Plan. Secondary Investigators include those scientists not included in the Science Plan, but to study core or fluid samples or conduct downhole experiments whose proposals have been approved by the Science Steering Group for the Creede Caldera Moat Drilling Project.

\section{OB.JECTIVES}

The objectives of this protocol are to insure that all drilling samples and related data collected during the CCM drilling project are properly handled and curated, and that a permanent physical record of the drill hole is provided for future studies.

Basic concepts for handling and curation of Scientific drilling samples and related data are as follows: 
1) Samples and data are owned by the USGS and represent a present and future national resource.

2) After appropriate analyses on site, the samples along with a suite of descriptive data from the drilling project will be permanently archived for future access at the USGS Core Research Center. As new scientific ideas and analytical tools become available, the archived splits will provide opportunities to restudy the material and hence maximize the value of this drilling project.

3) A portion of the core (the Working Split) will be available for sampling and analysis by the Principal Investigators and Secondary Investigators or their delegated representitives. It is the obligation of all scientists conducting experiments for this project to curate samples in their possession in such a manner as to preserve their integrity, identity, orientation, location, and minimize the amount of sample destroyed. Upon completion of the project studies, all remaining samples, with thin or polished sections, analytical results, notes and discriptions, and photographs will be archived at the USGS Core Research Center.

4) A timely and complete record of observations, measurements, and techniques will be added to the data base following each step of sample handling and analysis.

5) Deaccession of project samples and/or related data from archive facilities will occur only with joint approval of the USGS, ICG designated Science Panel, and CRC management.

\section{PERSONNEL AND RESPONSIBILITIES}

The final Science Plan for the CCM drilling project, as approved by the ICG, contains detailed information on the sampling program, including sampling priorities and intervals, as well as time to be allotted for down-hole sampling and logging. Figure 1 is a general organization chart (from the Creede Caldera Moat Drilling Project Management Plan) that indicates the responsibilties of and relationships between the various individuals for this project. Those responsibilities as they affect sample and data collection and handling are desribed below. 


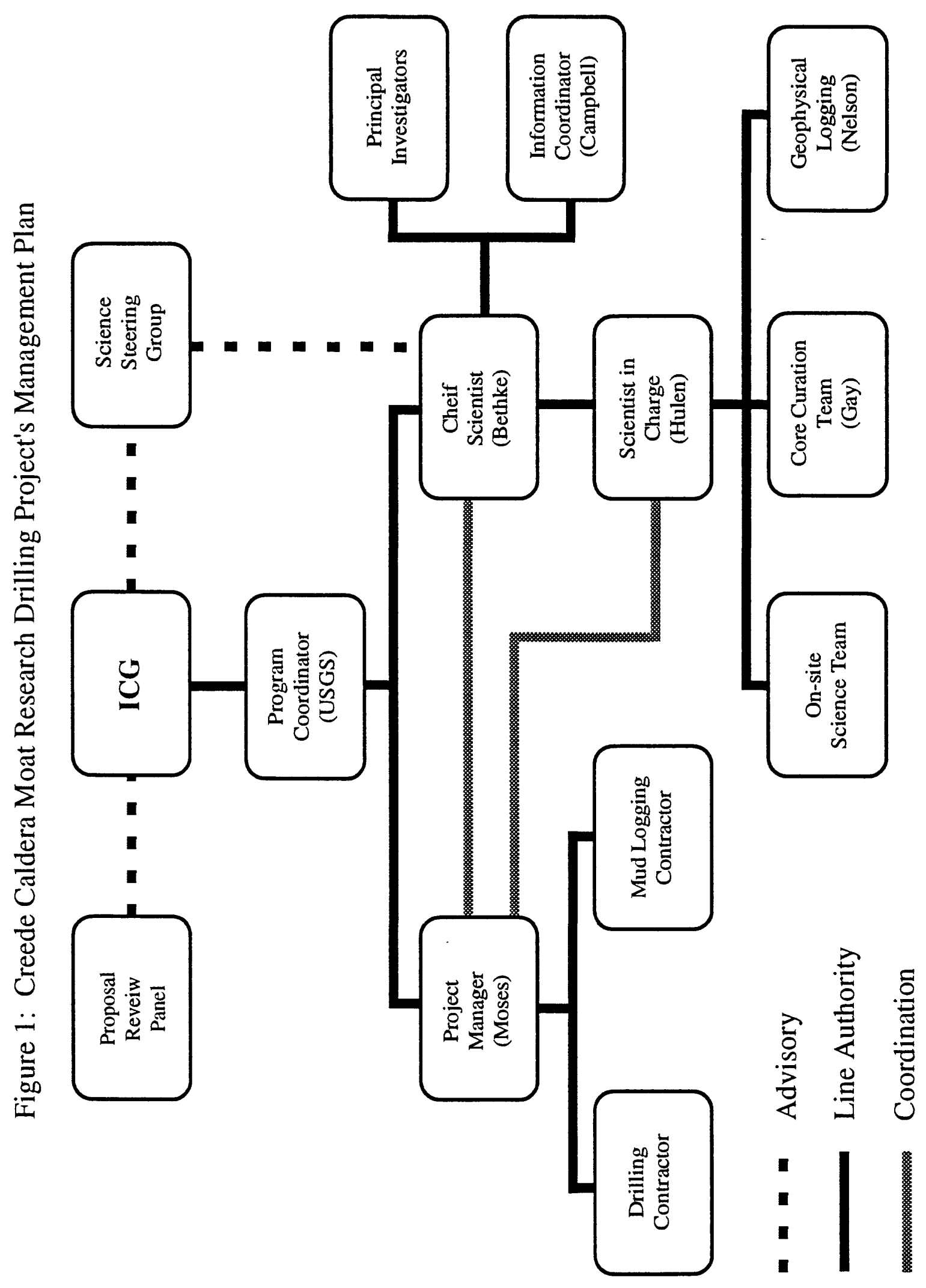


The Project Manager has overall responsibilty for the sucessful completion of the drilling program. As such he is resonsible for supervising contractors in all aspects of the operation, including drilling, coring, down-hole geophysical and mud logging, and for scheduling and coordination of sample collection activities. The Project Manager has authority over all on-site activities as they affect the drilling/coring operation.

The Chief Scientist is responsible for implementing and managing the Science Plan in such a way as to maximize its benefits and to insure that the requirements of all Principal Investigators are satisfied, and are consistent with drilling and engineering requirements.

The Scientist-in-Charge is responsible for the coordination and operation of all on-site scientific activities as described in the CCM Science Plan. These activities include: 1) the initial charaterization of project samples made available by the Sample Manager, 2) downhole geophysical logging and other downhole experiements, 3) fluid sampling and mud sampling, 4) maintenance of a drilling log, and 5) through the Sample Manager, onsite handling and curation of the core, fluid, and mud samples.

The Sample Manager supervises the Core Curation Team responsible for receiving samples from the drill rig floor and mud logger, and conducting and recording sample preparation (cleaning, marking, orientating, etc.), sample intergrity, boxing, on-site storage, and shipment of samples to the USGS Core Research Center.

The On-site Science Team is responsible for conducting and completing those on-site scientific activities for which the Scientist-in-Charge is responsible. This includes the initial lithologic logging and characterization of drill core. Additionally, the On-site Science Team will assist the Sample Manager with on-site collection, handling, and curation of the core, fluid, and mud samples whenever necessary.

The USGS Core Research Center Curator is responsible for the preparation and documentation of an Archive and Working Split; procurement, distribution, and documentation of project samples from the Working Split; and curation of all project cores, samples, thin and/or polished-sections etc., and data acquired from project samples. The CRC Curator also has the authority and responsibility to solicit return of project samples, data, and associated documentation.

The Logging Contractor is responsible for correlation of the geophysical logs collected downhole with the geophysical scans conducted on the core samples and the determination of true depth intervals from which cores were taken. The Logging Contractor is to provide a copy of all logs and depth determinations to the CRC Curator to be archived with the project samples.

The Science Steering Group, appointed by the Chief Scientist with the concurrence of the ICG, will provide guidance to the Chief Scientist, Project Manager, Scientist in Charge, and CRC Curator concerning changes in the Science Plan. It will be responsible 
for establishing the guidelines and the order of sampling based upon the priority (nondestructive before destructive, time-dependent before time-independent tests), nature, and analytical techniques of an experiment as detailed in the project's Science Plan. The Science Steering Group will evaluate and approve or deny all requests for samples or data from Secondary Investigators during the 2 year period following drilling. Any sampling requests not in accordance with the Science Plan, or questions and concerns about sampling priorities will be addressed by the Science Steering Group in coordination with the CRC Curator.

Principal Investigators or Secondary Investigators receiving samples are responsible for proper handling and curation to preserve the integrity of these materials. Unused portions of the samples (this includes, but is not limited to, unprocessed sample portions, powders and mineral separates, notre and descriptions, and photographs), thin and/or polished sections and analytical results, along with documentation of sample handling and processing history of each sample, are to be returned to the CRC Curator as outlined in the Science Plan.

\section{ON-SITE EOUIPMENT}

Facilities and equipment required for sample handling, standard analyses, and curation of drilling samples on-site will be provided by the USGS under the responsibility of the Sample Manager. Sample processing facilities and other temporary buildings or truck trailers will be available for on-site analyses, examination, and storage of samples.

Table 1 summarizes equipment to be provided by the USGS. Other analytical equipment required for on-site scientific studies will be provided by Principal Investigators.

\section{TABLE 1: ON-SITE SAMPLE PROCESSING EQUIPMENT PROVIDED BY THE USGS.}

\section{Facilities}

Intitial core handling facility (temporary layout shed)

Core Characterization and storage facility (two USGS trailers)

\section{Equipment}

Layout tables with long core trays/core racks

Core total gamma analyzer

Magnetic susceptibility analyzer

35-mm cameras for color photographs

Photo table with quartz lights

Binocular microscopes

Sample marking, measuring, and examination (hand lenses) equipment 
Water-cooled trim saw

Sink and water storage tank

Core storage boxes

Box stapler

Box banding machine

Core drying equipment (hair dryers)

Impliments for cleaning core (brushes, sponges, etc.)

\section{ON-SITE HANDLING AND SAMPLING PROCEDURES}

\section{GENERAL STATEMENT}

The CCM drilling project will involve the acquisition of continuous cores. Cuttings and fluid samples will be collected as specified in the project Science Plan. Fluid sampling will proceed after final temperature measurements have been made (at least 6 months after completion of drilling). Samples will undergo certain standard handling procedures under the direction of the Sample Manager prior to being transferred to the Scientist-inCharge and the Science Team for core characterization, and thence to the USGS Core Research Center Curator for splitting, archiving, and sampling for project studies. Principal Investigators requiring on-site samples for ephemeral properties must make any sampling arrangements and detail any special sampling procedures with the Sample Manager prior to core recovery. Figure 2 is a flow chart which summarizes core handling and curation activities.

\section{CORE HANDLING PROCEDURES}

Since coring will be conducted using wire-line techniques, handling and curation procedures begin when the core-barrel liner is removed from the hole. Under the supervison of the Sample Manager, or her delegate, the drilling and coring crew will remove the core from the inner tube and place it in the 24' PVC tray in the on-site core handling shed. When transferring the core sample, care will be taken to avoid disturbance or breaking of the core. Documentation for the various procedural steps will be maintained. Copies of documentation forms can be found in Appendix A.

In the on-site core handling shed, the core will be cleaned with water, pieced together and aligned, marked for up/down orientation, broken into 2 foot sections, and placed in core boxes or, when deemed necessary, in short PVC core trays for transport to the Core Characterization Trailer. The short PVC core trays are numbered sequencially and marked to dishtinquish top from bottom. Sections of core are to be placed so that the top or shallowest part of each coring run is in tray \#1. Core up/down orientation will be indicated by drawing two parallel lines on the core - one color line and one black line 
Figure 2: Flow diagram for core handling and curation.

$(\$, @, *$, and \# denote responsible manager - see below)

@. Remove core from inner tube. place in $24^{\prime}$ tray

* Clean, align, and mark core

I

* Break into 2' sections, box, and transport to core characteriztion trailer

\#* Total gamma emission and magnetic susceptibility scans

\#* Special sampling for ephemeral properties (from Science Plan) 1

\# Core geologic logging

\#* Photograph core in boxes

* Ship core to USGS Core Research Center

I

$\$$ Slab core into Archive and Working Splits

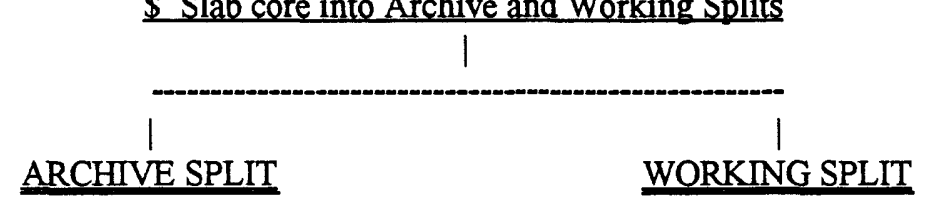

$\$$ Color Photography

$\$$ Sampling and distribution

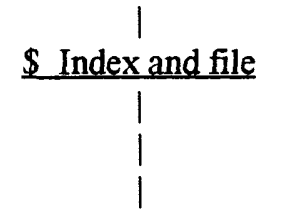

to $\mathrm{PI}^{2}{ }^{2}$

1

Analysis of sample(s)

by PI's

Non-destructive study

Return of remaining sample

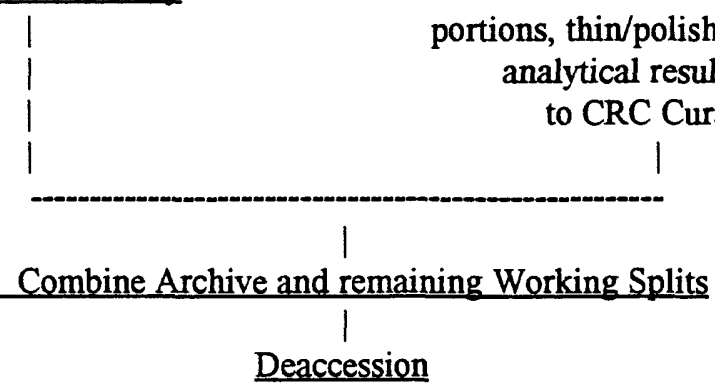

\$=CRC Curator, @ = Project Manager, * = Sample Manager, \# = Scientist-in-Charge

${ }^{1}$ To meet special requirements, as approved in the Science Plan or by the Science Steering Group, samples taken on-site may be taken earlier in the handling sequence.

2 The Principal Investigators receiving these samples for analyses are responsible for returning the unused portion(s) to the CRC Curator upon completion of analyses, along with any thin or polished sections, a descrpition of experimental techniques and methods applied to the sample(s), and copies of all analytical results. 
Figure 3: Examples of pen marks vs scribed lines to indicate core up/down orientation (gray line represents colored pen line).

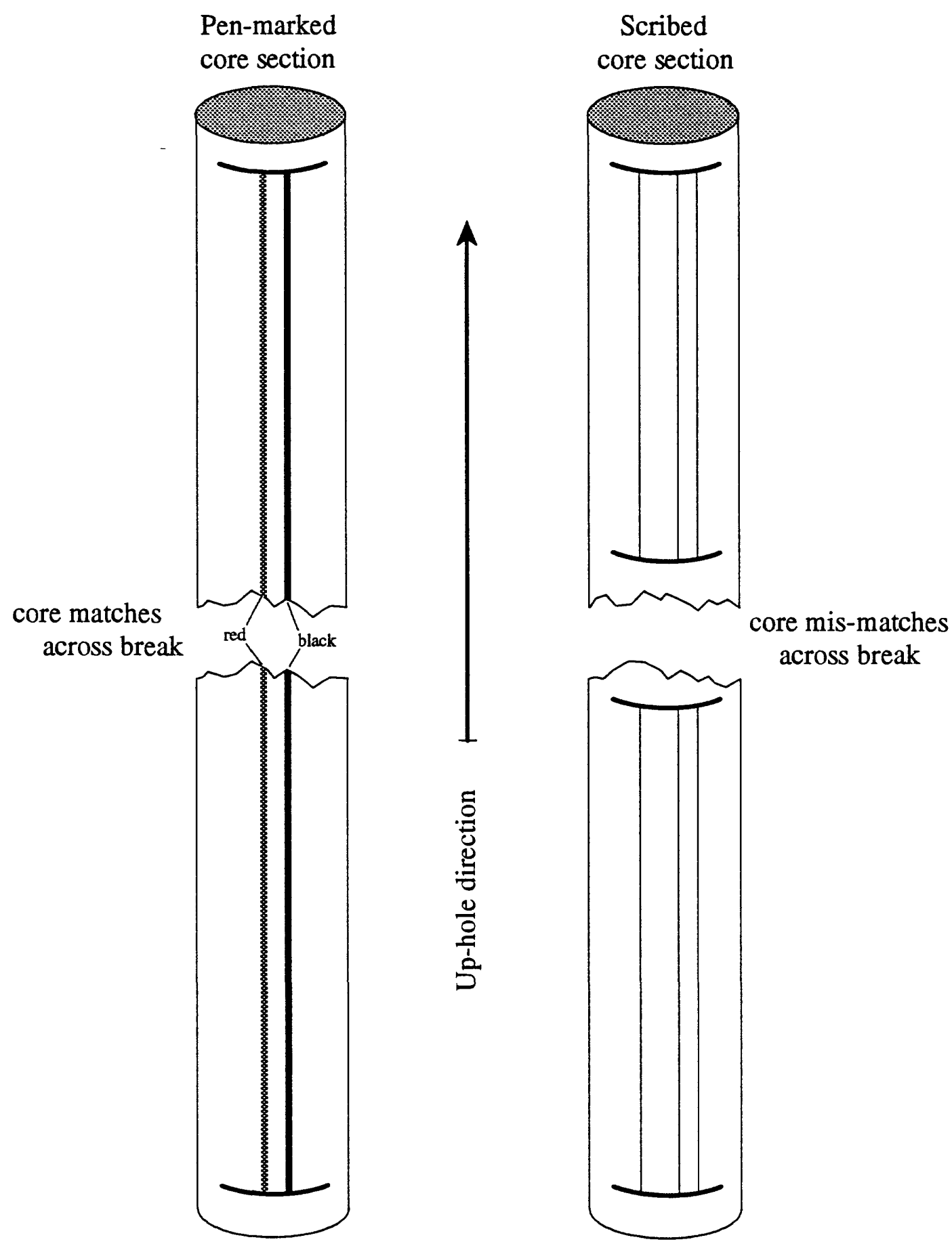


which is to the right when looking up the core. For those sections to be sampled for organic materials the core up/down orientation will be indicated by three parallel scribed lines, two set close together and one far apart, such that when looking up the core the two close-set scribed lines are to the right, see Figure 3. Any rubbled, non-coherent sections of core will be bagged and marked with the estimated relative footage for the interval.

Once in the Core Characterization Trailer the core will be put through the core-gamma and magnetic susceptibility units for later correlation with the down-hole gamma and magnetic susceptibility logs. The two foot core lengths will then be (re)placed into the core boxes. Since true-depth footages for the core sections will be determined at a later time the core sections will be labeled with relative footages, as described below.

Each coring run will be given a sequential number starting with the number "R1" for the top of the hole. Within each coring run, footages will be measured in feet relative to the shallowest point of the coring run starting at $0.0^{\prime}$ (eg. 1R3-4.6 for a relative footage at 4.6' down from the shallowest part of coring run \#3 from drill hole \#1). Correspondingly, all samples taken from the core will be identified by the the drill hole and coring run number designation followed by the shallowest relative footage number (ie. for a one foot long sample taken between $4.2^{\prime} \& 5.2^{\prime}$ of run \#5, drill hole \# 1, the sample ID would be 1R5-4.2). For samples with the same relative footage an aphabetic designation will be added to distinguish the samples (ie. 1R5-A4.2). If samples are to be split further, a letter and/or relative footage number should be added to the parent sample ID. Except for samples collected to be crushed and powdered, orientation data is to be maintained for all samples and subsamples. Figure 4 details this sample numbering system.

When placed in the core boxes each piece of core will be labeled with the core run number and relative run footage. In the case of core sections to be sampled for organics the run number and relative footage will not be written on the core but on a tag to be kept with that section. A $35 \mathrm{~mm}$ photogragph of each complete core box will be taken for documentation.

If studies of ephemeral properties are called for in the Science Plan, appropriate samples will be collected at this time. Each of these samples will be photographed (if sample is whole core, then both front and back will be photographed) and assigned a unique identification number before being removed from the core sample set. Spacer blocks, with the run number and relative footage for both the top and bottom of the sample noted, will be placed to fill any sections where whole core has been sampled. Following completion of the core handling operations the core will be turned over to the On-site Science Team for core characterization. 


\section{Figure 4: Core sample numbering protocol for the Creede Caldera Moat Drilling Project}

CCM-1

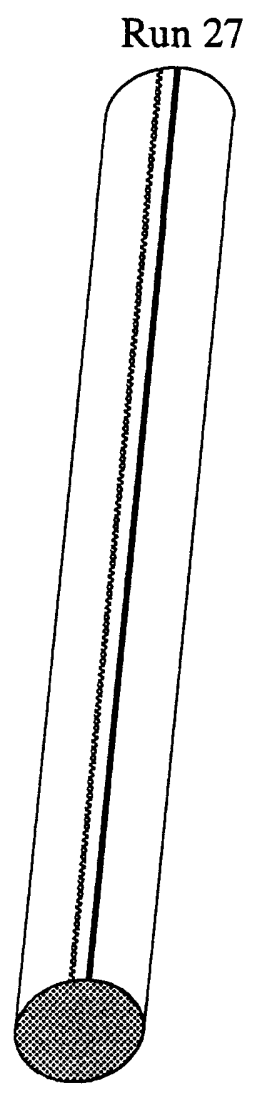

Archive Split

Use "P" plus powder type (eg py=pyrite sep., $x r d=x$-ray diff., etc.) in paraenteses designation for powdered subsamples and mineral separations

Add a pnuemonic in parentheses at end of subsample number to indicate end use (eg. ts-thin section, $\mathrm{dp}=$ polished

section, etc.)

Cut a notch on the up-side of thin and polished section to preserve oriention of subsamples

$$
\text { IR27-83.3-4.15-P(py) }
$$

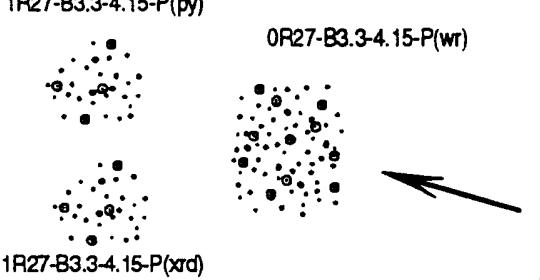

For each subsample cut transverse to core axis, use relative footage (in decimal feet measured from top of core run) of shallowest portion of subsample

For each (sub)sample cut parallel to core axis, use letters to distinquish subsamples

orientation for each (sub)sample must be maintained throughou t subsequent sampling splits

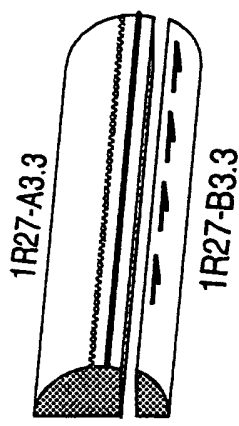




\section{CORE CHARACTERIZATION PROCEDURES}

Upon receipt of the core from the Sample Manager the Scientist-in-Charge and the Onsite Science Team will prepare a lithologic and fracture $\log$ with as much detail as time permits. Logging will be on standard forms (see Appendix A) designed with input from the Principal Investigators to include those characteristics, readily identified in hand specimen, that will provide guidance in later sampling for project studies. At a minimum, on-site logs shall include general lithologic features such as color (as judged against GSA color chart), grain size, sorting, induration, etc.; veins and vein-related alteration; and presence of organic material. Appendix B, Figures Bla \& B1b are examples of how the core logging sheets should look once they have been completed. Symbols, abbreviations, and lithologic types used in the core log can be found in Appendix B.

If a section of core contains special or oriented features that the On-site Science Team deems should be preserved within the archive slab, at least in part, they will mark such sections of core for slabbing orientation once the core logging has been completed. The slabbing orientation is to be desginated by marking a line with slash marks pointing uphole on the outside surface parallel to the core's axis. The slabbing cut will then be made perpendicular to the plane containing this surface line and the core's axis as illustrated in Figure 5.

As the Scientist-in-Charge deems neccessary, the Sample Manager will load the core boxes on pallets, wrap and strap them and arrange for their transportation to the USGS Core Research Center in Denver, CO.

\section{ON-SITE CORE SAMPLING PROCEDURES}

On-site sampling of core will be done only as directed by the Science Plan when necessary to preserve ephemeral properties of the core. On-site sampling may be done by appropriate Principal Investigator or by the on-site science team, but must be done under the supervison of the Sample Manager who shall assign a unique sample number to each sample and shall make careful records of the interval sampled, nature of the sample, time of collection, prior handling, name and location of the Principal Investigator, and purpose of sampling.

\section{CURATION AND ARCHIVING PROCEDURES}

At the CRC a longitudinal slab along the side of the core, at least 1 inch thick, will be made of each core section. This slab will become the Archive Split and be marked, photographed, and boxed by the CRC Curator or his delegate. The remainder of the core will be marked, and then become the Working Split for distribution to investigators under the direction of the CRC Curator as defined in the Science Plan. 
FIGURE5: Examples of pen marks to designate slabbing cut orientation.

Plane containing

core axis' slabbing orientation line

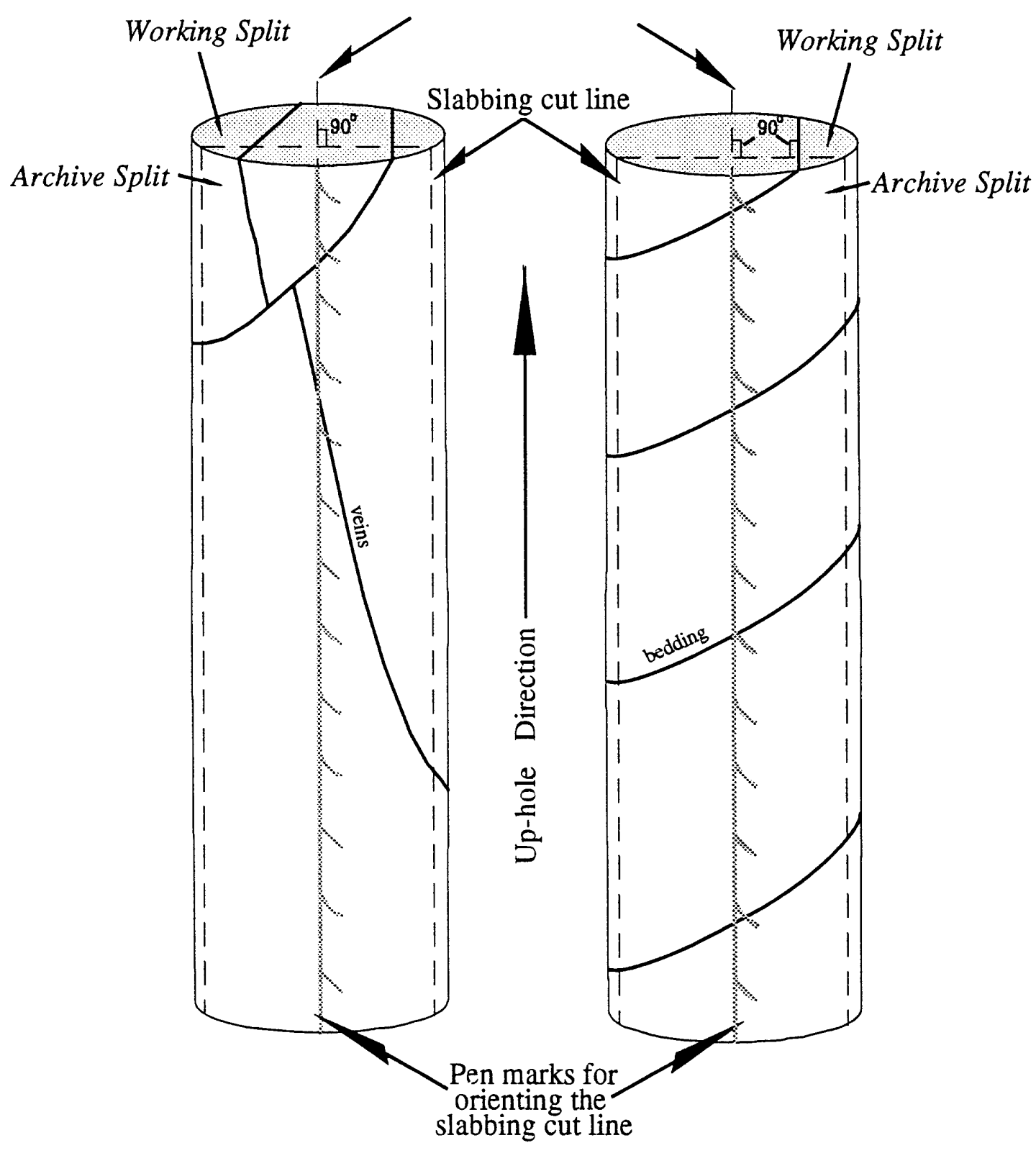




\section{Working Split}

After the entire core is slabbed and a set of Archive and Working Splits prepared, samples for experiments approved in the Science Plan or by the Science Steering Group may be taken according to the sampling priority and guidlines established by the Science Steering Group. No sample may be removed until assigned a unique identification number as described above.

For a period of two years following completion of drilling the project samples shall be protected from general distribution to allow Principal and Secondary Investigators to complete their studies. At the end of the two year protected period the Science Steering Gruop shall establish a policy and set of procedures for general distribution of samples to other investigators with the approval of the ICG. Within two years after distribution of samples all investigators shall return all samples and associated thin or polished sections, analyses, data compilations, etc., to the USGS CRC Curator to be merged with the Archive Split unless other arrangements are stipulated in the Science Plan or approved by the Science Steering Group. In the event that written permission is obtained from the Science Steering Group to keep samples at an intermediate sample archive, the USGS retains ownership of these samples and is responsible for decisions on deaccession of such samples.

\section{Archive Split}

The Archive Slab will be photographed in color and archived according to procedures described below. This slab will be preserved for visual inspection and examination, and no sampling will be allowed without approval from the ICG. At the USGS Core Research Center, the CRC Curator assumes responsibility for the maintenance of both Archive and Working Splits including indexing and filing for availability by the public 2 years after beginning of distribution to Principal and Secondary Investigators. Any decisions for deaccession of project samples will be made by the ICG.

\section{True Depth Determination and Marking}

After geophysical logging is completed, the Logging Contractor will correlate the gamma-ray emission and any other appropriate project-specific scans of the core with appropriate logs to determine the true depth intervals of the coring runs. These depth determinations will be sent to the CRC Curator, who will distinctively re-mark the Archive and Working Samples. Scientists working on samples distributed prior to true depth determination will be notified by the CRC Curator as to the true depth determinations. Samples should not be renumbered after true depth has been determined to reduce confusion and preserve consitancy of sample numbering scheme. 


\section{CUTTINGS}

During drilling, specified amounts of cuttings may be collected at regular depth intervals as prescribed in the Science Plan. If continuous coring does not provide adequate samples, the Scientist-in-Charge may direct collection of cuttings at more frequent depth intervals. Under the direction of the Sample Manager, cuttings will be collected, washed, and placed in properly labeled sample bags by the Mud Logger. The Sample Manager will send these samples to the USGS Core Reseach Center for indexing and filing.

\section{FLUIDS}

Collection of fluid samples will be identified in the Science Plan and may include samples of drilling mud and additives to provide information on contamination of core and formation fluids. Mud and additive samples will be collected by the Mud Logger under the direction of the Scientist-in-Charge. Some fluid analyses may be conducted by the project scientists at the drill site, whereas other chemical and isotopic constituents can be analyzed in laboratories if the samples are appropriately preserved with stabilizing agents and properly stored in containers.

Science Plans that require the collection of fluid samples as part of a project study will specify the collection method and the techniques for preservation.

\section{ARCHIVING PROCEDURES}

The CRC Curator and the project Sample Manager, will assign appropriate unique identification numbers to each sample. These identifiers will be used by all scientists and archive managers for documentation. The CRC Curator will keep a careful record of the identification number, nature and size, date of allocation, name of Invesitgator, and name and location of facility for each sample allocated for scientific investigation. Since samples associated with this drilling project may be exchanged between investigators at several locations, careful records will be taken by the appropriate Principal Investigator or intermediate Archive Manager and sent to the CRC Curator, whenever such exchange occurs. Scientists receiving samples must handle such materials in such a manner that unused portions so that they retain their proper vertical orientation and may be integrated into the Archive or Working Sample upon return to the Core Research Center.

Procedures for archiving drilling samples will follow those used by the USGS Core Research Center. Upon receipt, the sample and relevant data are cataloged and a permanent data card is entered into a file. Core boxes are given permanent labels containing a library number, the number of boxes from each drill hole, the drill hole identifier plus a sub-identifier if appropriate. This information is simultaneously entered into the archive's master file. Core boxes are then stored. 
Cuttings, thin sections, photographs, logs, and analytical data are stored in a manner specified by the CRC Curator and cross-referenced to samples collected from the same drill hole.

\section{SAMPLE DISTRIBUTION POLICY}

\section{GENERAL STATEMENT}

The policy for distribution of samples produced in the Creede Caldera Moat drilling project will be set by the Science Steering Group, and will follow generally that currently being used by the Ocean Drilling Program (JOIDES, 1985; Ocean Drilling Program, 1985). The following addresses are relevant to this policy:

John Sass, Chairman, Science Steering Group

Creede Calerda Moat Drilling Project

US Geological Survey

2255 North Gemini Drive

Flagstaff, AZ 86002

602-527-7226

U.S. Geological Survey

Core Research Center

Creede Caldera Moat Project Curator

Bldg 810, Entrance S-26

Mail Stop 975

(shipping address)

(mailing adress)

Denver Federal Center

Lakewood, CO 80225

303-236-1930

Distribution of samples is undertaken both to provide scientists with material to achieve the scientific objectives of the project, and to provide samples to conduct detailed studies beyond the scope of the CCM project Science Plan.

The CRC Curator is responsible for distributing - in accordance with the sample distribution guidlines established by the Science Steering Group - and preserving, as well as conserving, sample materials. The CRC Curator is responsible for maintaining a record of all samples that have been distributed, both on-site and subsequently from the archives, indicating the recipients and the nature of investigations proposed. This information is available to interested investigators on written request. Distribution of sample materials will be made from the USGS Core Research Center by the CRC 
Curator or designated representative(s). To meet special requirements, and with permission from the Science Steering Group, distribution may be made at the drill site by the project Scientist-in-Charge in consultation with the Sample Manager. In such instances the Sample Manager is responsible for maintaining a record of all samples so distributed.

\section{Sampling Limits}

Unless specified otherwise in the Science plan all core samples will be limited to one half of the Working Split and 6 inches in length. Investigators requesting larger amounts will provide justification for the larger sample sizes or for frequent intervals within the core. Such requests must be approved by the Science Steering Group in coordination with the CRC Curator.

Requests for samples from thin layers, stratigraphically important boundaries, sections that are badly depleted, or sections in unusually high demand, may be delayed in order to coordinate requests from other investigators. Exceptional sample requests will require more time for processing than routine requests.

No interval of the Working Split will be completely depleted without approval from the ICG Science Steering Group. A slab sample of core representing the Archive Split will be retained at the USGS Core Research Center in a pristine condition.

\section{SCIENCE PLAN EXPERIMENTS}

The project's Science Plan approved by the ICG will identify scientists (Principal Investigators) to receive samples for analyses. Allocation of samples to Principal Investigators will be done in accordance with the guidlines set up by the Science Steering Group. Principal Investigators wishing to acquire additional project samples not detailed in the Science Plan may submit a written proposal to the Science Steering Group. The request should include a statement on the nature of the proposed research, size and approximate number of samples required to complete the study, and any particular sampling technique or equipment required. Approval or disapproval will be based upon the scientific merits of the project and degree of overlap with studies by other investigators.

\section{NON-SCIENCE PLAN EXPERIMENTS}

Provision in the Science Plan is made to allow allocation of samples to investigators not identified in the Science Plan (Secondary Investigators)

The Science Steering Group may invite or approve applications from scientists who are not Principal Investgators to perform studies of selected samples. In such instances, a careful record of samples removed will be made by the Principal Investigator and Sample Manager. Such investigations will contribute to the project reports to the same extent as 
original participants in the Science Plan. All requirements of the Sample Distribution Policy apply to such secondary experiments.

\section{Sample Requests}

Researchers who wish to use samples for studies beyond the scope of the CCM project's Science Plan should submit sample requests to the Science Steering Group for consideration in coordination with the CRC Curator. Requestors are required to specify quantities and intervals of samples required, the nature of the proposed research, time required to complete the work and to submit results for publication, funding status, and availability of analytical equipment and space for the research.

Additionally, if the requestor has received samples previously, he will account for the disposition of the samples by citing published works, three copies of which must be sent to the CRC Curator. If no report has been published, the requestor will send a brief report on the status of the research. Unused and residual samples will be returned to the CRC Curator when the project has terminated.

Requests for samples from secondary investigators in government, academia, and industry will be honored in a similar manner as those from original investigators. Such researchers will be subject to the same obligations to publish results promptly in the open literature. Scientists examining CCM project samples will provide to the CRC Curator copies of reports published and of data acquired in their research.

Investigators who wish to study ephemeral properties may request a waiver of the waiting period. If approved, the requestor may join the original project scientists and incur obligations noted earlier in the section on supported experiments.

\section{Funding}

Creede Caldera Moat project samples will be distributed after the requestor provides the ICG Science Panel with evidence that funding for the proposed research is available, or unnecessary. If a sample request is dependent upon pending funding, ICG may, at its discretion, provide the proposed funding organization with information on the availability of suitable samples.

\section{Responsibilities}

Investigators who receive samples incur the following obligations:

1) To publish results promptly.

2) To acknowledge in publications that the samples were supplied by the USGS as part of the National Continental Scientific Drilling Program. 
3) To submit three (3) reprints of all published works to the CRC Curator.

4) To submit copies of all final analytical data obtained from the samples to the CRC Curator.

5) To return all unused or residual samples, in good condition and with a detailed explanation of any processing they may have experienced, upon termination of the proposed research. In particular, all thin or polished sections manufactured on-site or in the repositories are to be returned to the CRC Curator.

\section{REPOSITORIES}

The Archive and Working samples will be available for examination by interested parties at the USGS Core Research Center. The Working Sample may be sampled with the approval of the ICG Science Panel and the CRC Curator. Only the CRC Curator or delegate will remove samples from the archived materials.

\section{REFERENCE LIBRARY}

A reference library of CCM project-generated thin or polished sections, sample photographs, and drilling and analytical data will be maintained at the USGS Core Research Center for the use of visiting investigators. All thin sections produced on-site and in the project scientists' laboratories will eventually be availabale at this library. It is recognized that project scientists may require further use of thin or polished sections in post-drilling studies. These sections must be returned to the CRC Curator after a borrowing period of three (3) months. 


\section{REFERENCES}

Campbell, W.R., and Gay F. 1989. Core handling procedures used for the Cajon Pass, California, Deep Drilling Experiement: U.S. Geological Survey Open-File Rept. 89-496, $77 \mathrm{pp}$.

Goff, S. 1985. Curatorial policy guidelines and procedures for the Continental Scientific Drilling Program: Draft unpublished report, Los Alamos National Laboratories. 12pp. plus Field Procedures Manual.

JOIDES. 1985. Guide to the Ocean Drilling Program: JOIDES Journal, vol. XI, Spec. Issue No. 4. $93 \mathrm{pp}$.

Michalski, T.C. 1980. U.S. Geological Survey Core Library, Denver, Colorado, Administrative Report: Preliminary unpublished report, U.S. Geological Survey. 20pp.

Michalski, T.C., and Lineberger, W., 1990, Design and construction of a Mobile CoreProcessing Facility: USGS Open-File Report 90-344, 41 p.

Ocean Drilling Program (ODP). 1985. Shipboard Scientists Handbook, Ocean Drilling Program, Texas A \& M University: ODP Tech. Note No. 3. 170pp. 
APPENDIX A

Core Documentation Forms 
Creede Caldera Moat Scientific Drilling Project Core Log for Hole "CCM-1" (sheet 1 of 2)

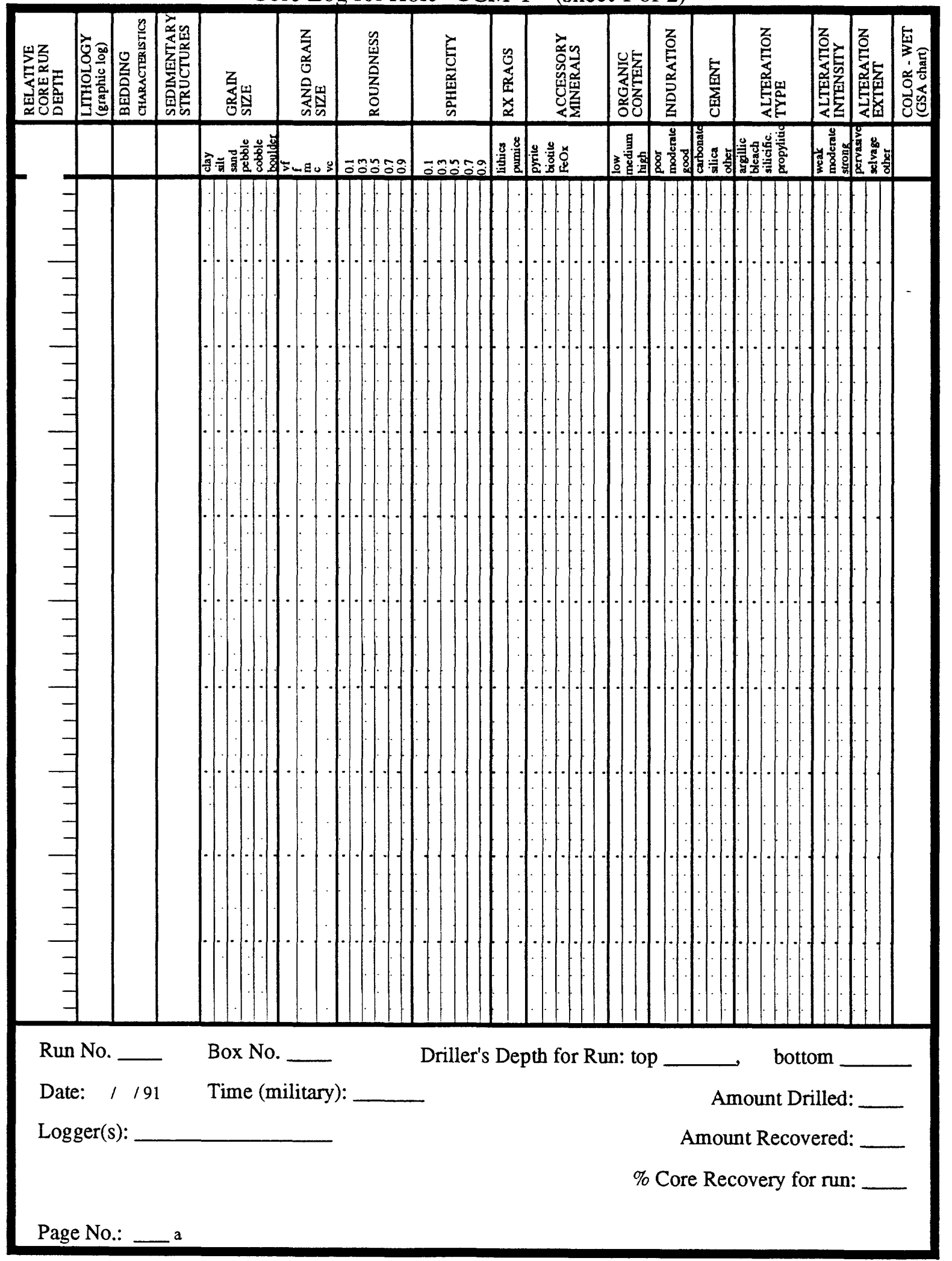


Creede Caldera Moat Scientific Drilling Project Core Log for Hole "CCM-1" (sheet 2 of 2)

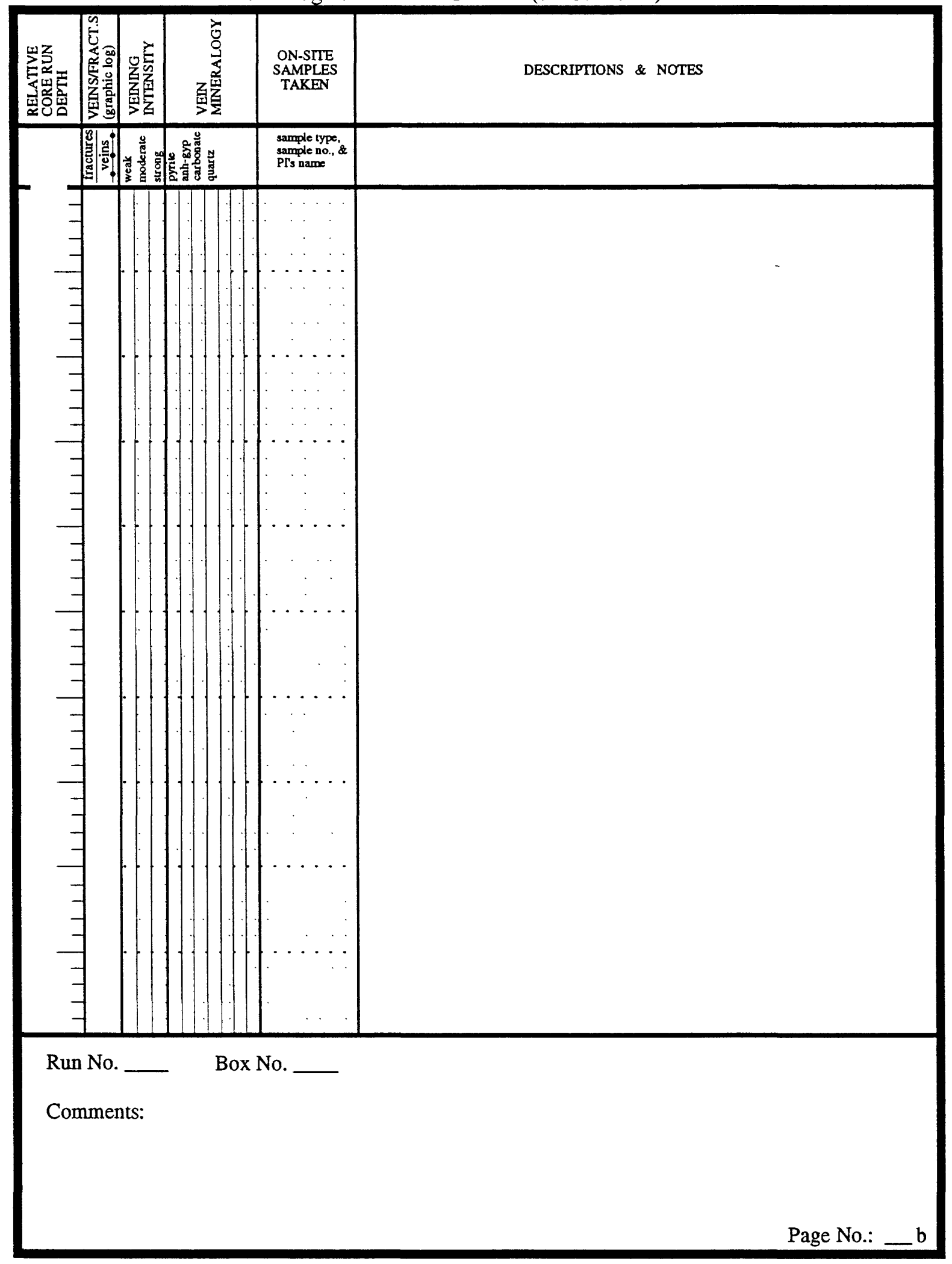




\section{CREEDE CALDERA MOAT SCIENTIFIC DRILLING PROJECT}

\section{Sample Request Form}

Investigator:

Phone No.: ( )____ FAX No.: ( )

Mailing address for samples:

Date of Request: / /

Purpose of Request (eg. petrography, geochemistry, etc.):

Type of analytical method (circle): Destructive - Nondestructive

Special sampling instructions (continue on separate page if necessary):

Complete and attach a copy of the Sample Request/Taken Form

Sample Request Filled By:

Name of USGS CRC Staff Member

Date: / /

Page 1 of 


\title{
CREEDE CALDERA MOAT SCIENTIFIC DRILLING PROJECT
}

\author{
Sample Request Form
}

\section{Responsibilities}

Investigators who receive samples incur the following obligations:

1) To publish results promptly; however, project-related reports may not be submitted for publication prior to twelve (12) months following the completion of the relevant project unless it is approved and authored by the original on-site scientists under the direction of the Principal Investigator.

2) To acknowledge in publications that the samples were supplied by the USGS as part of the National Continental Scientific drilling program.

3) To submit three (3) reprints of all published works to the CRC Curator.

4) To submit one copy of all final analytical data obtained from the samples to the CRC Curator.

5) To return all unused or residual samples, in good condition and with a detailed explanation of any processing they may have experienced, upon termination of the proposed research. In particular, all thin or polished sections manufactured on-site or in the repositories are to be returned to the CRC Curator.

Page 1 of 


\section{CREEDE CALDERA MOAT SCIENTIFIC DRILLING PROJECT Sample Request Form}

Investigator

Date

Page of

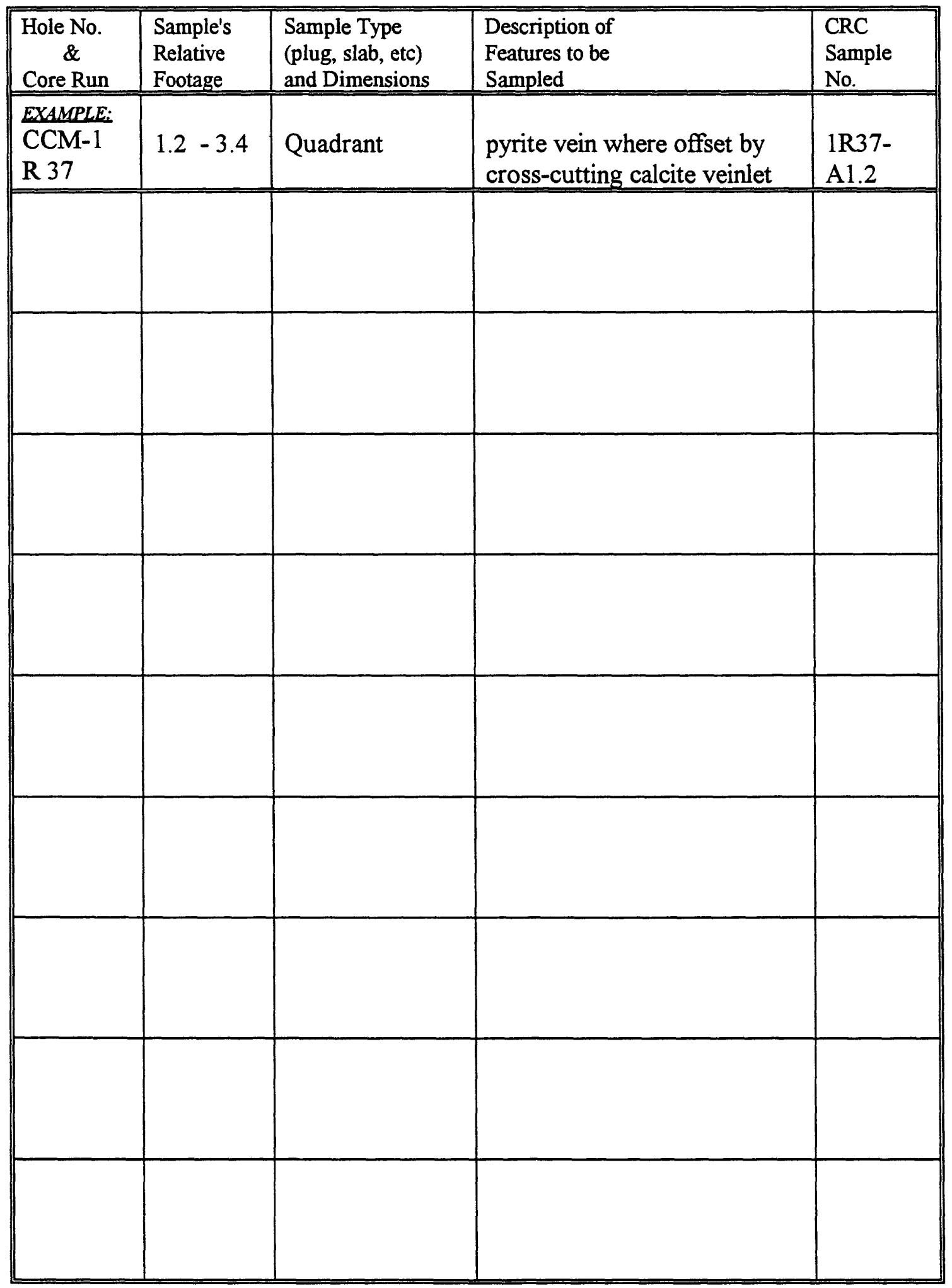


CREEDE CALDERA MOAT SCIENTIFIC DRILLING PROJECT $35 \mathrm{~mm}$ Photo Log

\begin{tabular}{|c|c|c|c|c|c|c|}
\hline Hole No. & Box No. & $\begin{array}{l}\text { Roll } \\
\text { No. } \\
\end{array}$ & $\begin{array}{l}\text { Photo } \\
\text { No. }\end{array}$ & F-stop & Date & Comments \\
\hline & & & & & & \\
\hline & & & & & & \\
\hline & & & & & & \\
\hline & & & & & & \\
\hline & & & & & & \\
\hline & & & & & & \\
\hline & & & & & & \\
\hline & & & & & & \\
\hline & & & & & & \\
\hline & & & & & & \\
\hline & & & & & & \\
\hline & & & & & & \\
\hline & & & & & & \\
\hline & & & & & & \\
\hline & & & & & & \\
\hline & & & & & & \\
\hline & & & & & & \\
\hline & & & & & & \\
\hline & & & & & & \\
\hline & & & & & & \\
\hline
\end{tabular}

Page 
CREEDE CALDERA MOAT SCIENTIFIC DRILLING PROJECT

Core Run Depth Log

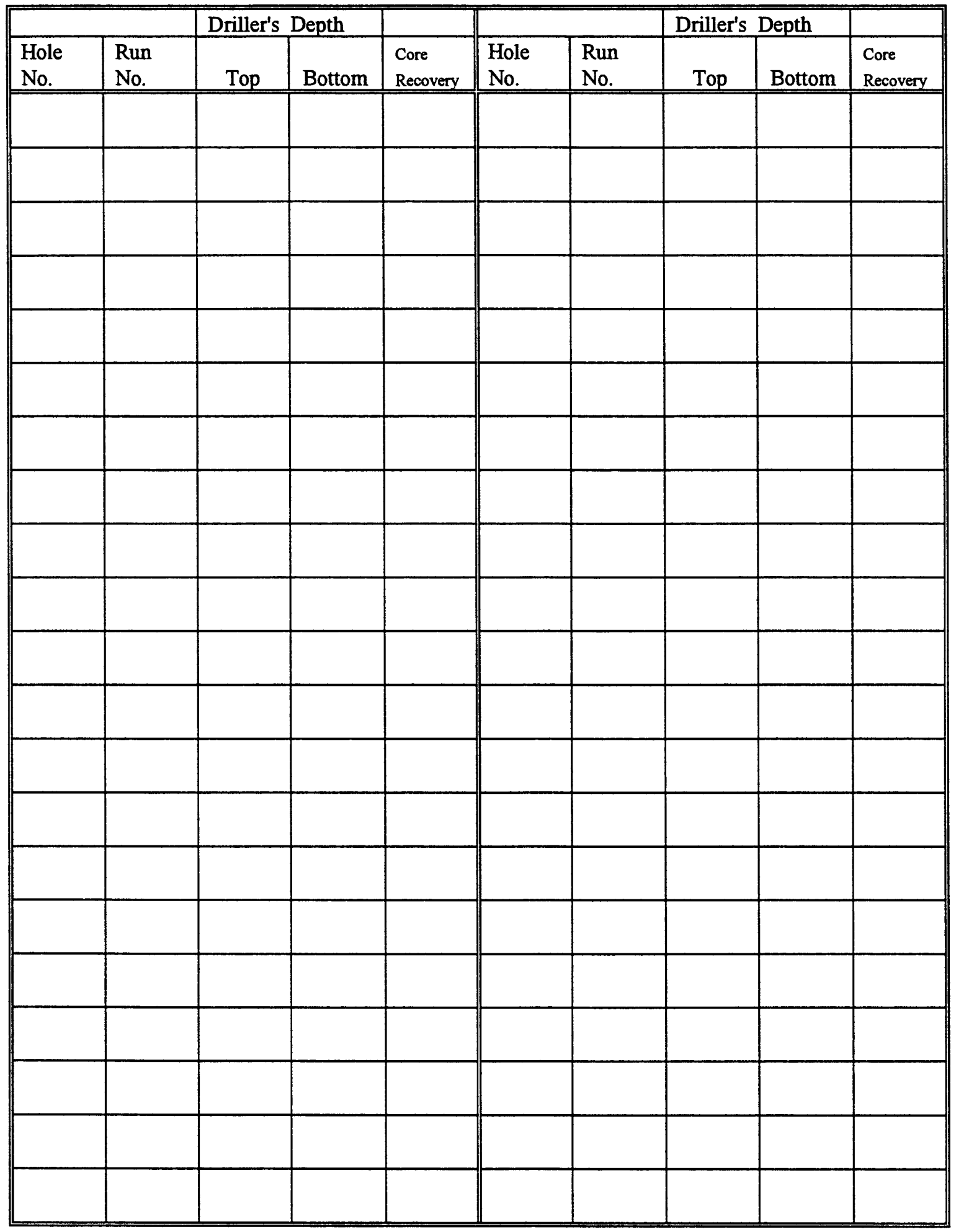


CREEDE CALDERA MOAT SCIENTIFIC DRILLING PROJECT Core Processing check List

\begin{tabular}{|c|c|c|c|c|c|c|c|c|}
\hline Box No. & $\begin{array}{c}\text { Washed } \\
\text { Oriented } \\
\text { Marked } \\
\end{array}$ & $\begin{array}{c}\gamma \text {-ray } \\
\text { Logging }\end{array}$ & $\begin{array}{l}\text { Magnetic } \\
\text { Suscept. } \\
\text { Logging } \\
\end{array}$ & $\begin{array}{l}\text { Geologic } \\
\text { Logging }\end{array}$ & $\begin{array}{c}\text { Special } \\
\text { Samples } \\
\text { Taken } \\
\end{array}$ & $\begin{array}{l}\text { Photo- } \\
\text { graphy }\end{array}$ & $\begin{array}{c}\begin{array}{c}\text { Other } \\
\text { (specify) }\end{array} \\
\end{array}$ & $\begin{array}{c}\text { Date } \\
\text { Shipped } \\
\text { to } \\
\text { Archive } \\
\end{array}$ \\
\hline & & & & & & & & \\
\hline & & & & & & & & \\
\hline & & & & & & & & \\
\hline & & & & & & & & \\
\hline & & & & & & & & \\
\hline & & & & & & & & \\
\hline & & & & & & & & \\
\hline & & & & & & & & \\
\hline & & & & & & & & \\
\hline & & & & & & & & \\
\hline & & & & & & & & \\
\hline & & & & & & & & \\
\hline & & & & & & & & \\
\hline & & & & & & & & \\
\hline & & & & & & & & \\
\hline & & & & & & & & \\
\hline & & & & & & & & \\
\hline & & & & & & & & \\
\hline & & & & & & & & \\
\hline & & & & & & & & \\
\hline
\end{tabular}

Core Hole No. 
CREEDE CALDERA MOAT SCIENTIFIC DRILLING PROJECT

On-site Core Sample Record

\begin{tabular}{|c|c|c|c|c|c|c|c|c|c|}
\hline \multirow[b]{3}{*}{ Date } & \multirow[b]{3}{*}{$\begin{array}{l}\text { Hole } \\
\text { No. }\end{array}$} & \multirow[b]{3}{*}{$\begin{array}{l}\text { Box } \\
\text { No. } \\
\end{array}$} & \multirow[b]{3}{*}{$\begin{array}{l}\text { Run } \\
\text { No. }\end{array}$} & \multirow[b]{3}{*}{$\begin{array}{l}\text { Rel. Depth Interval } \\
\& / \text { or Sample Number }\end{array}$} & \multicolumn{5}{|c|}{ Core Sample Type (please initial) } \\
\hline & & & & & \multicolumn{2}{|c|}{ Whole Core } & \multicolumn{2}{|c|}{ Plugs \& Chips } & \multirow[b]{2}{*}{$\begin{array}{l}\text { Other (specify) } \\
\text { \& Comments }\end{array}$} \\
\hline & & & & & $\begin{array}{l}\text { Geother. } \\
\text { (Decker) }\end{array}$ & $\begin{array}{l}\text { Organic } \\
\text { (Leven) }\end{array}$ & $\begin{array}{l}\text { Fluids } \\
\text { (Conca) }\end{array}$ & $\begin{array}{l}\text { Prelim } \\
\text { XRD \& } \\
\text { Petrol. }\end{array}$ & \\
\hline & & & & & & & & & \\
\hline & & & & & & & & & \\
\hline & & & & & & & & & \\
\hline & & & & & & & & & \\
\hline & & & & & & & & & \\
\hline & & & & & & & & & \\
\hline & & & & & & & & & \\
\hline & & & & & & & & & \\
\hline & & & & & & & & & \\
\hline & & & & & & & & & \\
\hline & & & & & & & & & \\
\hline & & & & & & & & & \\
\hline & & & & & & & & & \\
\hline & & & & & & & & & \\
\hline & & & & & & & & & \\
\hline & & & & & & & & & \\
\hline & & & & & & & & & \\
\hline & & & & & & & & & \\
\hline
\end{tabular}


CREEDE CALDERA MOAT SCIENTIFIC DRILLING PROJECT Drilling Fluid \& Additive Sample Log

\begin{tabular}{|c|c|c|c|c|c|}
\hline Sample Number & Date & Time & Sample Type & $\begin{array}{l}\text { Handler's } \\
\text { Initials } \\
\end{array}$ & Comments \\
\hline & & & & & \\
\hline & & & & & - \\
\hline & & & & & \\
\hline & & & & & \\
\hline & & & & & \\
\hline & & & & & \\
\hline & & & & & \\
\hline & & & & & \\
\hline & & & & & \\
\hline & & & & & \\
\hline & & & & & \\
\hline & & & & & \\
\hline & & & & & \\
\hline & & & & & \\
\hline & & & & & \\
\hline & & & & & \\
\hline & & & & & \\
\hline & & & & & \\
\hline & & & & & \\
\hline & & & & & \\
\hline & & & & & \\
\hline
\end{tabular}




\section{APPENDIX B}

Core Logging Sheets, Lithology Index, Symbols, Class Definitions and Abbreviations 
Figure B1a: Example of a completed core log for the Creede Caldera Moat Research Drilling Project

Creede Caldera Moat Scientific Drilling Project

Core Log for Hole "CCM-1" (sheet 1 of 2)

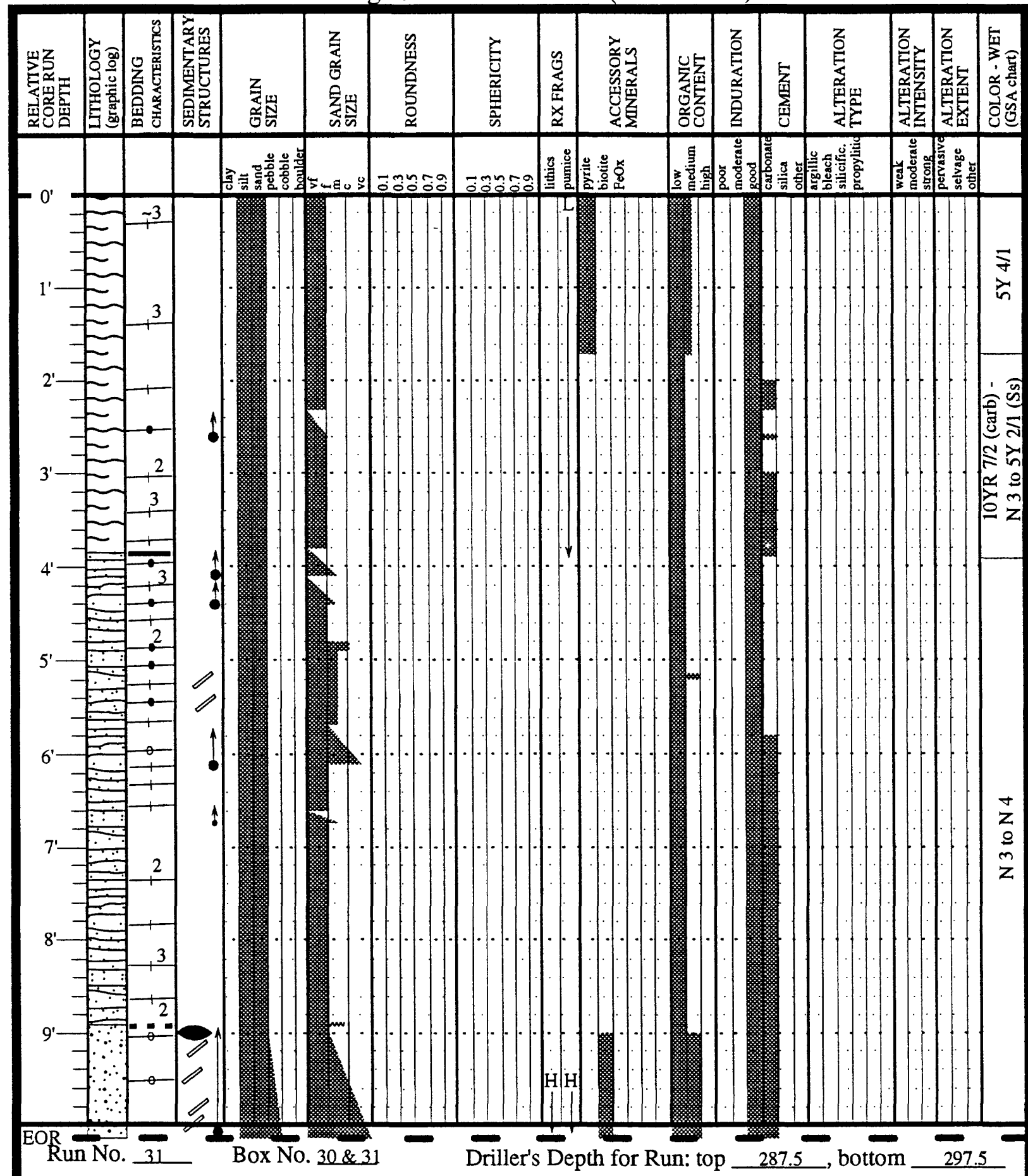

Date: 10/13/91 Time (military): $\sim 01: 30$

Amount Drilled: 10.0

Logger(s): JH \& DH

Amount Recovered: 10.2

$\%$ Core Recovery for run: $102 \%$

Page No.: $\quad 31$ a 
Figure B1b: Example of a completed core log for the Creede Caldera Moat Research Drilling Project.

\section{Creede Caldera Moat Scientific Drilling Project}

Core Log for Hole "CCM-1" (sheet 2 of 2)

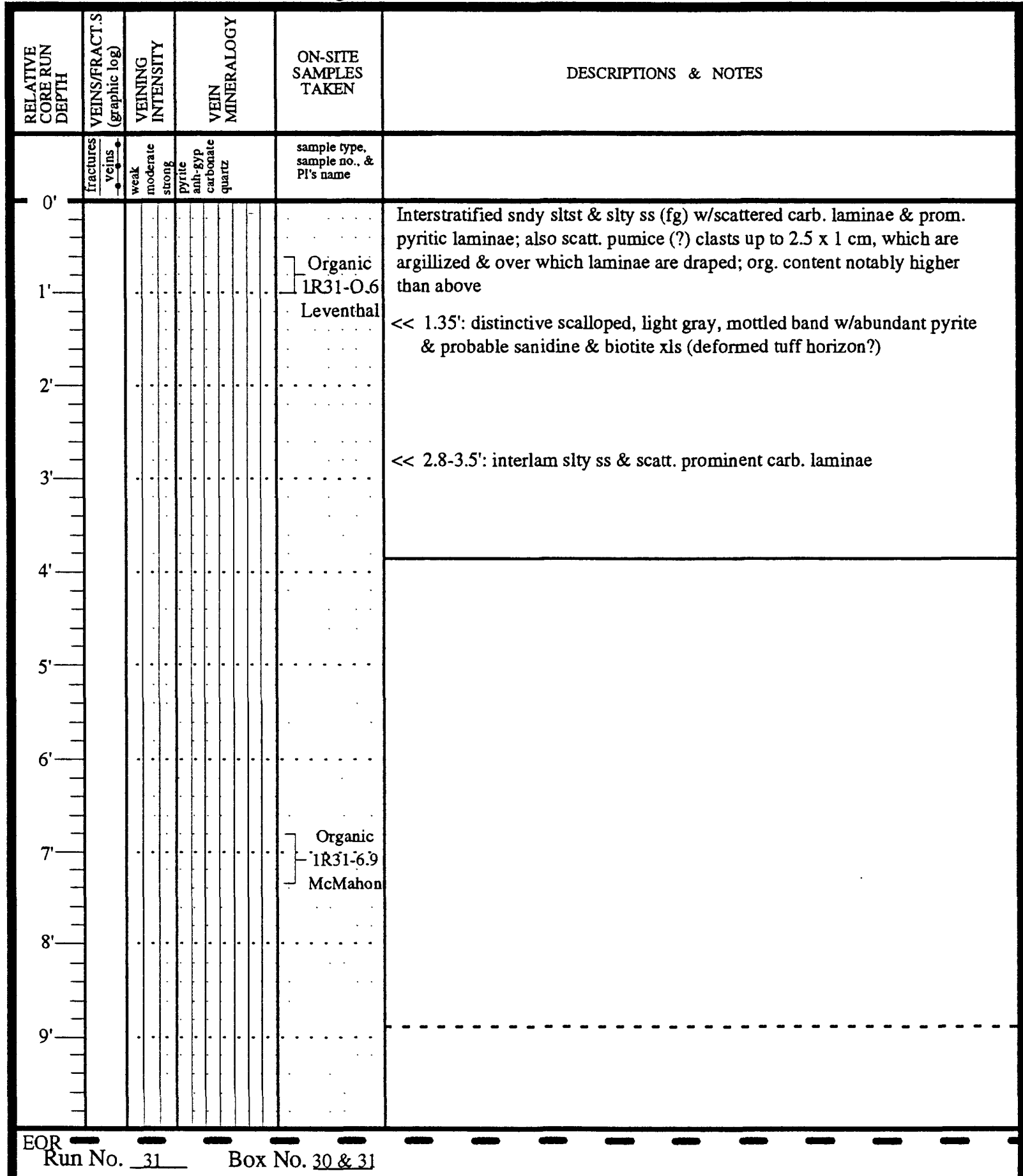

Comments: 
Figure B2: Creede Caldera Moat Drilling Project lithologic patterns and number index for the core log sheet "Lithology" column.

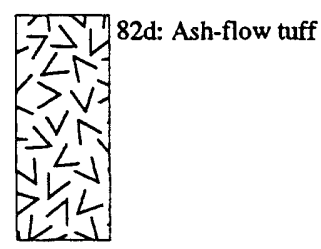

132a: Interbedded siltstone to sandstone w/ reworked tuff
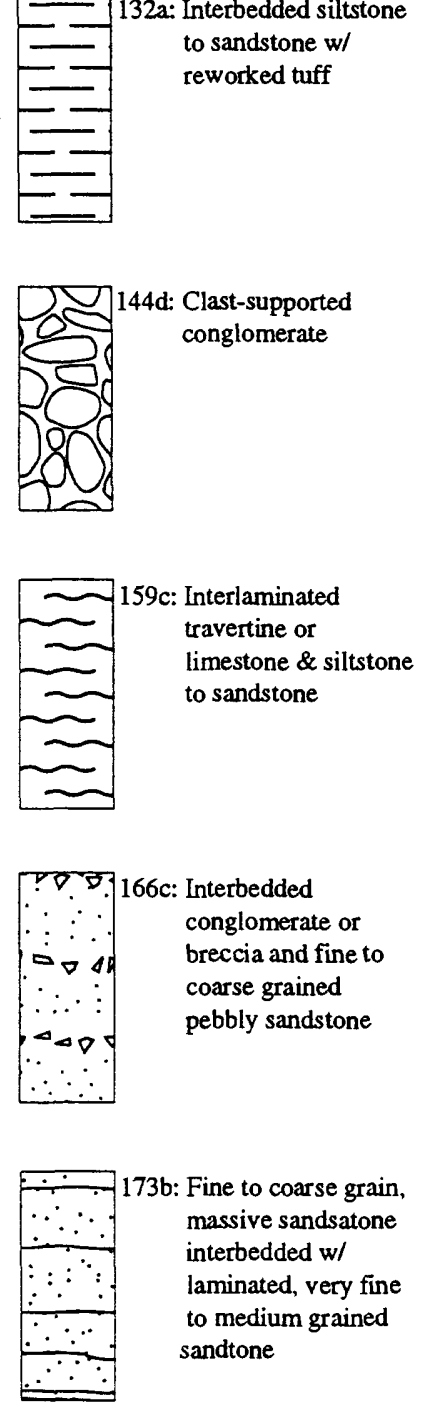

73b: Fine to coarse grain, massive sandsatone interbedded $w /$ laminated, very fine to medium grained sandtone
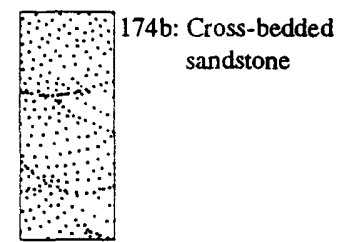
sandstone

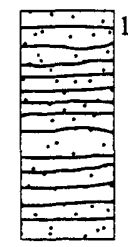

$75 \mathrm{~d}$ : Interlaminated, very fine to fine gr. silty sandstone $w /$ beds of fine to coarse gr. sandstone
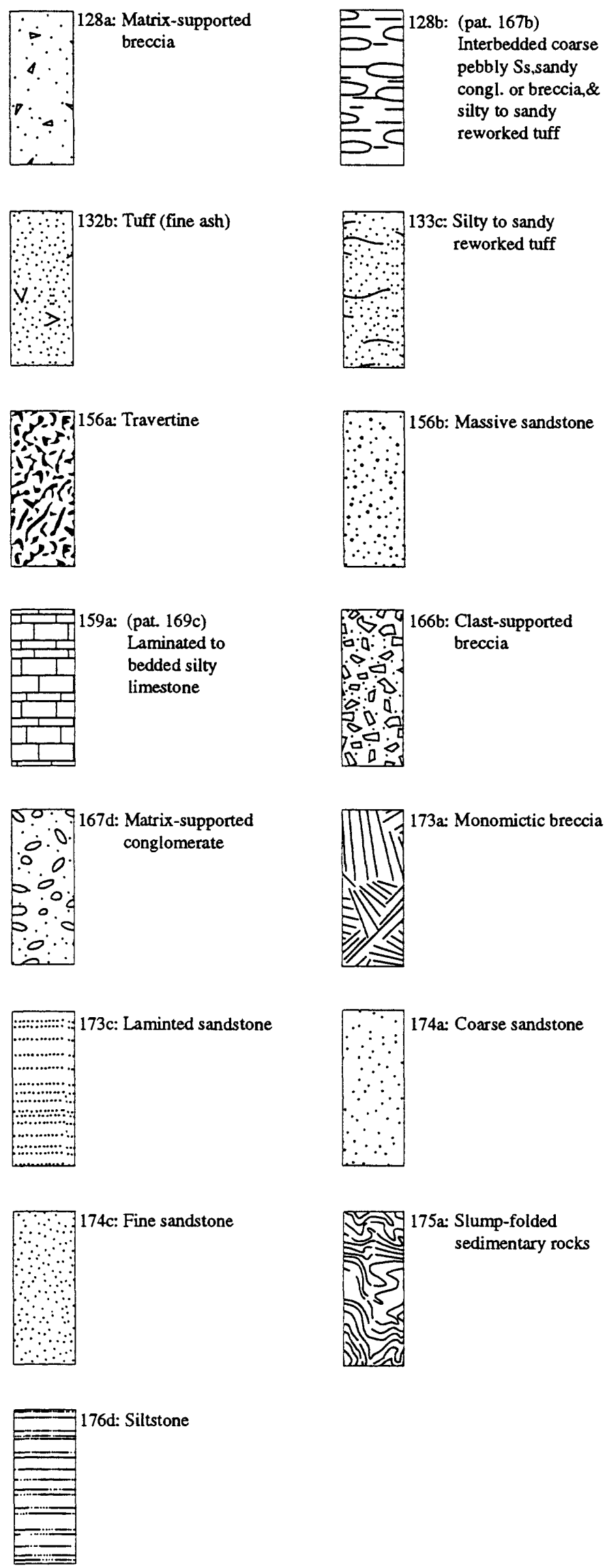
Figure B3: Explanation of symbols and patterns in core log column entries for the Creede Caldera Moat Research Drilling Project.

\section{"Relative Core Run Depth" Column Symbols}

EOR End-of-run marker

Break in core

BAG Bagged rubble interval

\section{"Bedding Characteristics" Column Symbols}

\section{Bedding Type}

$+\quad$ Laminated bedding $(<1 \mathrm{~cm})$

$\rightarrow \quad$ Thin-bedded $(1-10 \mathrm{~cm})$

$\rightarrow \quad$ Medium-bedded $(10-30 \mathrm{~cm})$

$\rightarrow \quad$ Thick-bedded $(>30 \mathrm{~cm})$

* Massive bedding

$-?-\quad$ Indistinct bedding

$u$ Wavy bedding

14 (number indicates dip of bedding or contact relative to core's axis)

\section{Bedding Contact}

- Sharp contact

Unconformal contact

-.. Gradational contact

???? Indeterminate contact

2 Fault contact

\section{"Vein" Column Symbols}
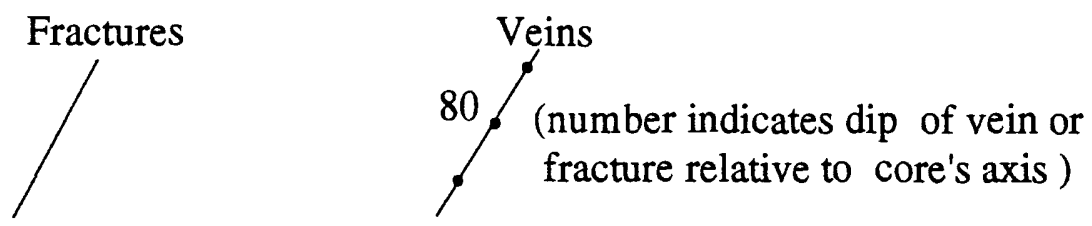
Figure B3 cont.: Explanation of symbols and patterns in core log column entries for the Creede Caldera Moat Research Drilling Project.

\section{"Sedimentary Features" Column Symbols}

\section{Structures}

25 Load cast

$\checkmark$ Flute cast

$\checkmark$ Groove cast

《I Cross bedding

m Convolute bedding

$\Lambda$ Injection structure

$\Omega$ Flame structure

Geopetal structure

000 Imbrication

- Mudcracks

- Rain-drop impression

$\simeq$ Ripple marks (non-directional)

$\pi$ Ripple marks (directional)

Rip-up clast

le Rip-up clast (calcareous)

a Breccia

\section{Fossils}

$\lambda$ Root casts

(G) Animal fossil

$\varnothing \quad$ Plant fossils

$S$ Bioturbation

ก Algal bumps

$\theta$ Burrows
Concretion

mM Styolites

$\diamond \quad$ Vugs

"rice-grain" psuedomorph (calcite after Ikaite?)

$\triangle$ Autoclast

$\triangle$ Autoclast (calcareous)

$\succ$ Penecontemporaneous faulting

if Scour-and-fill

? Questionable feature

$\uparrow_{\mathrm{L}}$ Gradded bedding (arrow points in direction of fining; add a "P" for pumice grading or "L" for lithic grading next to the ball end of the symbol)

Reverse gradded bedding 


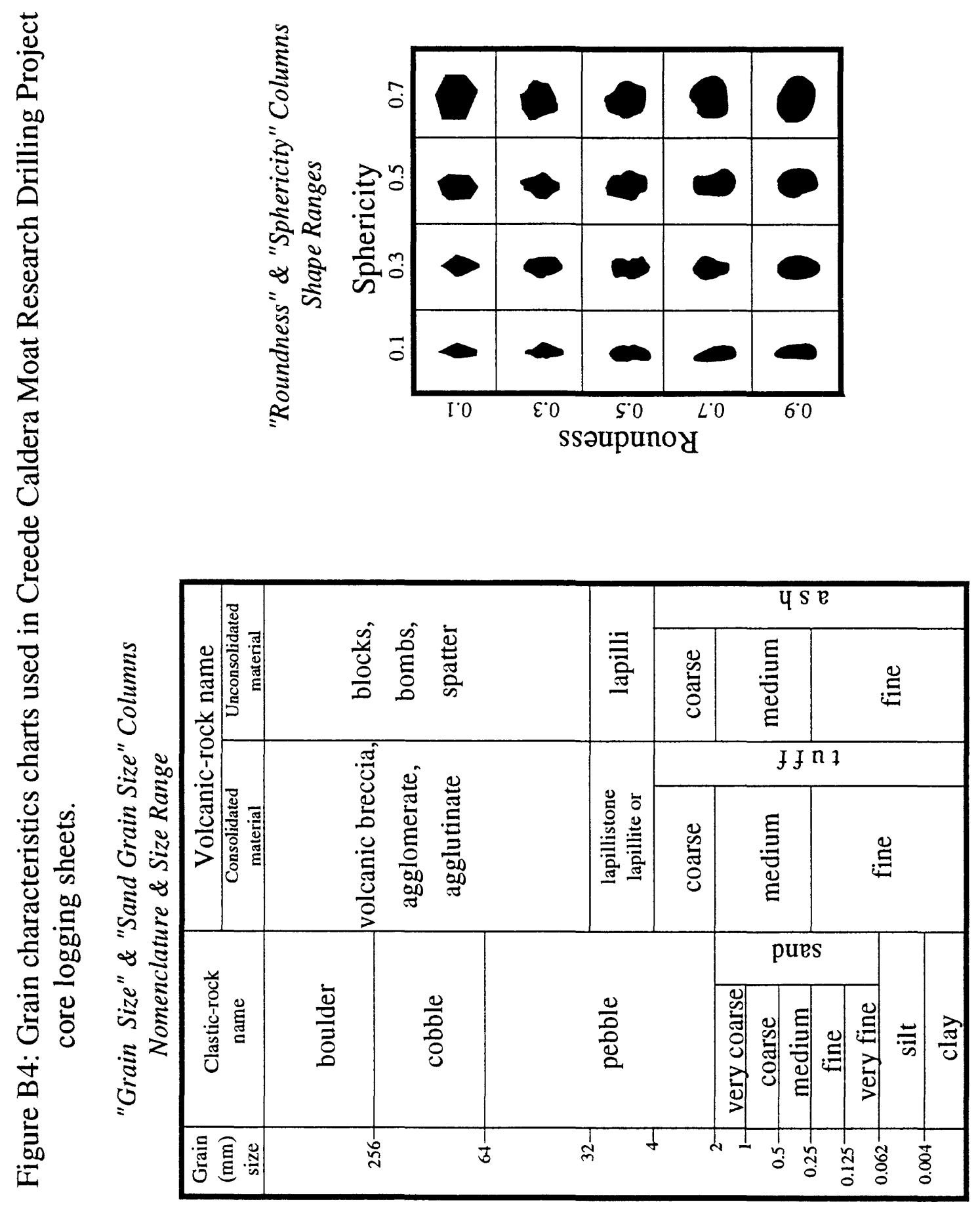


Table B1: Abbreviations for the Creede Caldera Moat Research Drilling Project geologic logs.

GENERAL TERMS

aggregate

amoeboid

anhedral

apparent(ly)

average

banded

becoming

bladed

blocky

botryoidal

casing

cavity

centimeter

coarse

columnar

concentrated

crack

crooked

definitely

densely

diameter

disseminated

dominant(ly)

dominated

downward

drilling

elongate

equant

escape

especially

euhedral

except

fiber(s)

fine

foot

for example

form

frequently

generally

grease

intermediate

irregular

least
AGGR

AMOE

AHN

APP

AVG

BNDD

BEC

BLDD

BLKY

BOT

CSNG

CAV

$\mathrm{CM}$

C

COLM

CONC

CRK

CRKD

DEF

DNS(LY)

DIA

DISS

DOM

DOMTD

DWNWD

DRLNG

ELNGT

EQNT

ESC

ESP

EUH

EXC

FIB

F

FT

E.G.

FRM

FREQ

GEN

GRS

INTM

IRREG

LST lost-curculation material

LCM

magnetic

major

mark

massive

medium

metal

metallic

millimeter

moderate(ly)

mold

most

mottled

narrow

MGTC

MAJ

MK

MSV

MED

MET

METLC

MM

M

MLD

MST

MTLD

NAR

occupied(ing)

OCC

OPQ

PTLY

PVSV

PTTD

POL

POR

POSS

PWDRY

PR

PRSM

PROB

PROM

PNKY

RDD

SCTD

SEP

SEQ

SEV

SHP

SHRP

SHV

SNS

SL

SFT

STD

STNG

STL

STRT

$S$

STRUC

STBY

SURF 
Table B1 (cont.): Abbreviations for the Creede Caldera Moat Research Drilling Project geologic logs.

\begin{tabular}{|c|c|c|c|}
\hline texture & TEXT & clay & CLY \\
\hline thick(ly) & THK(LY) & clinoptilolite & CLPT \\
\hline thin(ly) & THN(LY) & cobble & CBL \\
\hline trace & TR & conglomerate & CGL \\
\hline translucent & TRANSL & covellite & $\mathrm{CV}$ \\
\hline transparent & TRANSP & & \\
\hline truncated & TRUNC & $\begin{array}{l}\text { debris } \\
\text { dolomite }\end{array}$ & $\begin{array}{l}\text { DEB } \\
\text { DOL }\end{array}$ \\
\hline upward & UPWD & dolostone & DLST \\
\hline very & V & evaporite & EVAP \\
\hline wavy & WVY & feldspar & FSP \\
\hline weak(ly) & $\mathrm{W}$ & fluorite & FL \\
\hline wispy & WSPY & fluvial & FLUV \\
\hline with & W/ & formation & FM \\
\hline without & WO/ & fragment & FRAG \\
\hline cross & $\mathrm{x}$ & galena & GN \\
\hline crystal & $\mathrm{XI}$ & gaylussite & GAYL \\
\hline crystalline & $\mathrm{XLN}$ & glass & GLS \\
\hline crystallized & $\mathrm{XIZD}$ & goethite & GOE \\
\hline & & gravel & GRVL \\
\hline feature eludes charac. & $\# @ * * \%++!$ & gypsum & GYP \\
\hline & & hematite & HEM \\
\hline \multicolumn{4}{|c|}{ LITHOLOGY AND MINERALOGY } \\
\hline & & ignimbrite & $\begin{array}{l}\text { IGNM } \\
\text { IK }\end{array}$ \\
\hline alkali feldspar & $\mathrm{KF}$ & ikaite & $\mathbb{I}$ \\
\hline alluvium & ALLUV & illite & IL \\
\hline amygdaloidal & AMYG & & \\
\hline analcime & ANC & jarosite & JAR \\
\hline andesite & AND & jasperoid & JASP \\
\hline anhydrite & ANH & & \\
\hline argillaceous & ARG & kaolin & KA \\
\hline ash-flow tuff & AFT & lacustrine & LAC \\
\hline barite & $\mathrm{BA}$ & landslide & LSLD \\
\hline basalt & BSLT & lapillus, lapilli & LAP \\
\hline biotite & BIOT & latite & LAT \\
\hline boulder & BLDR & leucoxene & LEUC \\
\hline breccia & $\mathrm{BX}$ & limestone & LS \\
\hline & & lithic & LTHC \\
\hline calcareous & CALC & littoral & LITT \\
\hline calcite & $\mathrm{CAL}$ & & \\
\hline carbonaceous & CRBN & magnetite & MT \\
\hline carbonate & CARB & marcasite & MARC \\
\hline chalcedony & CHAL & metamorphic & MET \\
\hline chalcocite & $\mathrm{CC}$ & mineral & MINRI \\
\hline chalcopyrite & CPY & mordenite & MORD \\
\hline chert & CHT & mudstone & MDST \\
\hline chlorite & CHL & & תות \\
\hline clastic & CLSTC & $\begin{array}{l}\text { opal } \\
\text { organic }\end{array}$ & $\begin{array}{l}\text { OP } \\
\text { ORG }\end{array}$ \\
\hline
\end{tabular}


Table B1 (cont.): Abbreviations for the Creede Caldera Moat Research Drilling Project geologic logs.

\begin{tabular}{|c|c|c|c|}
\hline phenocryst & PHENO & $\begin{array}{l}\text { breccia } \\
\text { brecciated }\end{array}$ & $\begin{array}{l}\text { BX } \\
\text { BXTD }\end{array}$ \\
\hline plagioclase & PLAG & & \\
\hline plutonic & PLUT & channel & $\mathrm{CHNL}$ \\
\hline porphyritic & PPYTC & clast & CLST \\
\hline porphyry & PPY & coarsening & CRSNG \\
\hline pyrite & PY & concretion & CNCR \\
\hline pyroclastic & PYR & contact & СTCT \\
\hline & & convolute & CVLT \\
\hline quartz & QTZ & & \\
\hline & & deformation & DEFM \\
\hline rhodochrocite & RHOD & densely welded & DW \\
\hline rhyolite & RHY & deposit(ed) & $\mathrm{DEP}(\mathrm{TD})$ \\
\hline rock(s) & $\mathrm{RX}$ & dessicated & DESS \\
\hline & & devitrified & DEVIT \\
\hline sand & SND & & \\
\hline sandstone & SS & extrusive & EXTR \\
\hline sandy & SNDY & & \\
\hline sanidine & SAN & fiamme & FIAM \\
\hline sediment(ary) & SED & fining & FNG \\
\hline sericite & SER & fissile & FSL \\
\hline shale & SH & flarne & FLM \\
\hline shard & SHD & foliation & FOLN \\
\hline siliceous & $\mathrm{SIL}$ & fossil & FOS \\
\hline silt & SLT & fragment & FRAG \\
\hline siltstone & SLTST & frosted & FRSTD \\
\hline silty & SLTY & & \\
\hline silver & $\mathrm{Ag}$ & graded & GRDD \\
\hline sinter & SIN & grain(ed) & GR \\
\hline smecite & SM & & \\
\hline sphalerite & SPH & intrusive & INTR \\
\hline stibnite & STIB & iron oxide & $\mathrm{FeOx}$ \\
\hline talus & TAL & laminae(ted) & LAM \\
\hline tetrahedrite & TET & lenticular & LENT \\
\hline travertine & TRV & lineation & LIN \\
\hline tuff & $\mathrm{TF}$ & & \\
\hline & & mantle & MNTL \\
\hline vitric & VTT & mod. welded & MW \\
\hline volcanic & VOLC & & \\
\hline 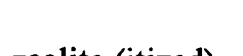 & & porphyritic & PPYTC \\
\hline zeolite (itized) & ZEOL & & \\
\hline & & raindrop & RNDRP \\
\hline & & ripple & RPL \\
\hline PRIMARY F & & & תחת \\
\hline accretionary & ACCR & $\begin{array}{l}\text { scoured } \\
\text { slumped }\end{array}$ & $\begin{array}{l}\text { SCRD } \\
\text { SLMP(D) }\end{array}$ \\
\hline armored & ARM & vesicle, vesicular & VES \\
\hline ball-and-pillow & $B \& P$ & & \\
\hline bedded & $\mathrm{BDD}$ & weakly welded & WW \\
\hline bedding & BDNG & & \\
\hline bipyramidal & BIPYR & cross (e.g. X-bdd) & $X$ \\
\hline
\end{tabular}


Table B1 (cont.): Abbreviations for the Creede Caldera Moat Research Drilling Project geologic logs.

\section{SECONDARY FEATURES}

alteration

altered

argillized

breccia

brecciated

calcareous

cement(ed)

chloritized

clast

coated

diagenesis(tic)

drusy

faulted

flooding

fracture(d)

gouge

hydrothermal

indurated

manganese oxide

mineralized

oxidized

pseudomorph

rubble

rubblized

replaced

replacement

selvage

sericitized

siliceous

silicified

slickensides

solution

stained

stockwork

unoxidized

vein(ed)
ALTN

ALT

ARGLZD

BX

BXTD

CALC

CMT(D)

CHLTZD

CLST

CTD

DIAG

DRU

FLT(D)

FLDNG

FRX(D)

GG

HYD

IND

MnOx

MINRLZD

OXDZD

PSDM

RBL

RBLZD

RPL

RPLMT

SLVG

SERCTZD

SIL

SILCRD

SLX

SOLN

STN(D)

STKWK

UNOX

$\mathrm{VN}(\mathrm{D})$ $\begin{array}{ll}\text { veinlet } & \text { VNLT } \\ \text { weathered } & \text { WTHD }\end{array}$

COLORS AND VALUES

black BLK

blue BL

brown BRN

gray GRY

green GRN

pink PNK

purple PPL

red $\mathrm{RD}$

yellow YEL

white WHT

orange ORNG

dark DK

light LT

medium MED

*(add "SH" to color designation when used as modifiers) 